\title{
Sieve-like preretinal exudates in Stenotrophomonas maltophilia endogenous endophthalmitis
}

\author{
Dinesh Suhan, ${ }^{1}$ Raghavendra Rao Kolavali, ${ }^{1,2}$ Anup Kelgaonkar (i) ${ }^{1}$
}

${ }^{1}$ Vitreo-retina, LV Prasad Eye Institute Bhubaneswar Campus, Bhubaneswar, India

'Vitreo-retina, All India Institute of Medical Sciences, Bibinagar, India

\section{Correspondence to Dr Anup Kelgaonkar; anupnk2008@gmail.com}

Accepted 12 July 2021

\section{Check for updates}

(C) BMJ Publishing Group Limited 2021. No commercial re-use. See rights and permissions. Published by BMJ.

To cite: Suhan D, Kolavali RR, Kelgaonkar A. BMJ Case Rep 2021;14:e244392. doi:10.1136/bcr-2021244392

\section{DESCRIPTION}

A 26-year-old woman presented with symptoms of sudden diminution of vision in the left eye for 4 days. She also had pain and redness in her left eye. She was a primigravida and had a spontaneous abortion at 8 weeks' gestation, which was managed by a gynaecologist with intravenous medications and fluids. Two weeks after the management of miscarriage, she developed ocular symptoms.

On examination, the right eye was unremarkable with best-corrected visual acuity (BCVA) 20/20. In the left eye, she had a perception of hand movements close to face with accurate light projection in all quadrants. On examination, she had lid oedema, conjunctival congestion, $3+$ cells in the anterior chamber (AC), posterior synechiae, fibrin in the $\mathrm{AC}$ and vitreous exudates. Diagnosis of endogenous endophthalmitis (EE) was made; pars plana vitrectomy with vitreous biopsy was performed in the left eye, followed by injection of intravitreal antibiotics (vancomycin and ceftazidime) and dexamethasone. Intraoperatively, vasculitis along with preretinal, sieve-like exudates, sparing the posterior pole, was observed. Urine and blood culture showed no growth. Growth of gram-negative bacilli was seen in vitreous culture. Gram-negative bacilli were identified as Stenotrophomonas maltophilia by the VITEK-2 system. The organism was observed to be sensitive to amikacin, ciprofloxacin, colistin and gentamycin while being resistant to imipenem, chloramphenicol and ceftazidime. Oral ciprofloxacin $(750 \mathrm{mg}$ two times per day for 1 week) was prescribed in the postoperative period. Intravitreal amikacin and dexamethasone were injected twice with an interval of 48 hours. In the postoperative period, preretinal exudates in a sieve-like pattern were noted. The exudates resolved gradually (figure 1). At 8-week follow-up, BCVA was 20/30 in the left eye, the AC was quiet and an early epiretinal membrane was noted with a few preretinal exudates in the mid-periphery (figure 2).

Endogenous endophthalmitis, a potential blinding ailment, occurs due to the hematogenous spread of microorganisms. The incidence of EE is lower than postsurgical and post-traumatic endophthalmitis. ${ }^{1}$ Predisposing factors include intravenous drug abuse, immunosuppression, the recent history of intravenous drug administration and prolonged intensive care. ${ }^{2}$ In Southeast Asia, gram-negative organisms are responsible for most EE cases. ${ }^{3}$

S. maltophilia (earlier known as Pseudomonas maltophilia and Xanthomonas maltophilia) is an aerobic, motile, non-fermenting, gram-negative rod. ${ }^{3}$ S. maltophilia infection can cause bacteraemia,

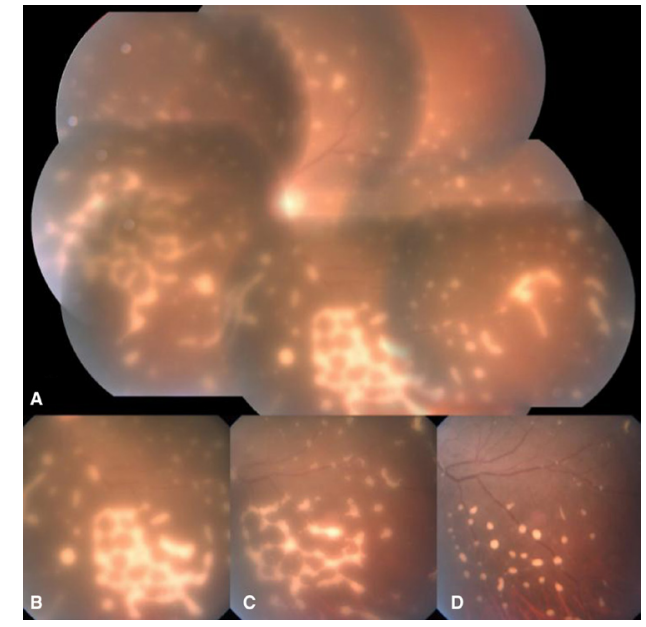

Figure 1 (A) Fundus montage image of the left eye 1 week after surgery showing sieve-like preretinal exudates inferiorly and nasally, multiple round preretinal scattered lesions are seen as well. Vitritis causing grade 3 vitreous haze is noted. (B) An enlarged image of (A) demonstrating sieve-like exudates. Gradual resolution of vitreous haze and preretinal exudates were seen during postoperative week 2 (C) and week 4 (D).

pneumonia, urinary tract infection, endocarditis, meningitis, peritonitis and/or ocular infections. ${ }^{4}$ Other than EE, S. maltophilia is known to cause acute conjunctivitis, scleral buckle infections,

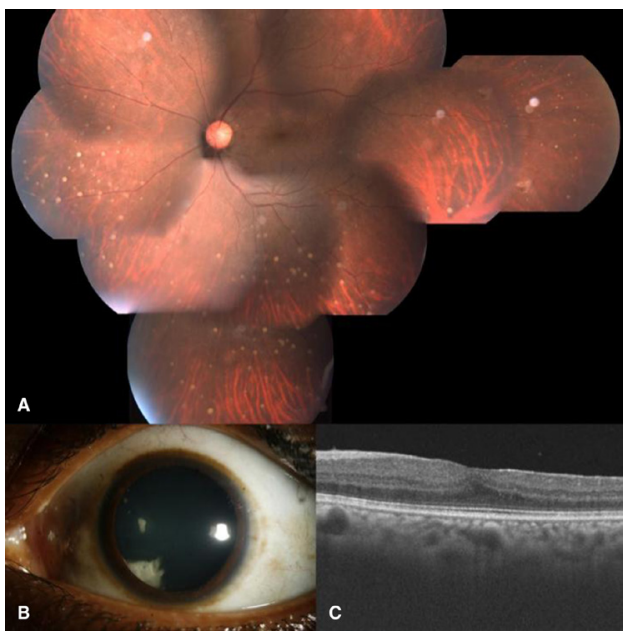

Figure 2 (A) Fundus montage image of the left eye 8 weeks after surgery. Resolution of vitreous haze is seen with a few residual preretinal precipitates. These precipitates resolved slowly over the next 3 months. She also developed a focal cataract (B) and had an epiretinal membrane during this visit (C). 
infantile dacryocystitis and preseptal cellulitis. ${ }^{5}$ It is resistant to many antimicrobial agents and sometimes antimicrobial resistance may emerge during therapy.

Poor prognosis in EE is seen in cases with delayed diagnosis, high virulence of the causative organism, presence of exudates at the posterior pole and poor baseline BCVA. Earlier reports by Chang et $a l^{6}$ and Chhablani et $a l^{7}$ had shown variable recovery in cases of $S$. maltophilia EE. They demonstrated antibiotic sensitivity to fourth-generation fluoroquinolones and

\section{Patient's perspective}

I am thankful to the treating physician who made me aware of endogenous endophthalmitis in my left eye. I was clearly intimated about the immediate requirement for vitreo-retinal surgery and study of the organism causing infection. After surgery, I was prescribed medications as per the antibiotic sensitivity reports. My vision recovered gradually over the period of 1-1.5 months. I was also made aware of possibility of this infection being either acquired or manifested after the intravenous treatment for miscarriage that I had 2 weeks before my eye condition.

\section{Learning points}

- Stenotrophomonas maltophilia endogenous endophthalmitis can be seen after intravenous fluid or drug administration.

- Antibiotics of choice for S. maltophilia are fourth-generation fluoroquinolones and chloramphenicol. Chloramphenicol resistance may occur as seen in our case.

- A sieve-like pattern of preretinal exudates which resolved along with the resolution of ocular inflammation was a characteristic finding in our case. chloramphenicol. Deviating from these reports, the organism in our case was resistant to chloramphenicol and susceptible to amikacin, ciprofloxacin, colistin and gentamycin. Also interestingly, the exudates which were in a sieve-like pattern resolved gradually with treatment. These are possibly inflammatory debris or aggregates. The resolution of these exudates coincided with the resolution of ocular inflammation.

Twitter Anup Kelgaonkar @ak_doc

Contributors DS contributed to manuscript writing and literature review. RRK and AK were responsible for the concept, review of literature, manuscript review and editing.

Funding This study was funded by Hyderabad Eye Research Foundation (LVPEIbcr-2021-244392-2021).

Competing interests None declared.

Patient consent for publication Obtained.

Provenance and peer review Not commissioned; externally peer reviewed.

\section{ORCID iD}

Anup Kelgaonkar http://orcid.org/0000-0002-3983-4200

\section{REFERENCES}

1 Cunningham ET, Flynn HW, Relhan N, et al. Endogenous endophthalmitis. Ocul Immunol Inflamm 2018;26:491-5.

2 Ness T. [Endogenous endophthalmitis]. Ophthalmologe 2007:104:935-9.

3 Wong JS, Chan TK, Lee HM, et al. Endogenous bacterial endophthalmitis: an East Asian experience and a reappraisal of a severe ocular affliction. Ophthalmology 2000;107:1483-91

4 Denton M, Kerr KG. Microbiological and clinical aspects of infection associated with Stenotrophomonas maltophilia. Clin Microbiol Rev 1998;11:57-80.

5 Penland RL, Wilhelmus KR. Stenotrophomonas maltophilia ocular infections. Arch Ophthalmol 1996;114:433-6.

6 Chang JS, Flynn HW, Miller D, et al. Stenotrophomonas maltophilia endophthalmitis following cataract surgery: clinical and microbiological results. Clin Ophthalmol 2013;7:771-7.

7 Chhablani J, Sudhalkar A, Jindal A, et al. Stenotrophomonas maltophilia endogenous endophthalmitis: clinical presentation, antibiotic susceptibility, and outcomes. Clin Ophthalmol 2014;8:1523-6.

Copyright 2021 BMJ Publishing Group. All rights reserved. For permission to reuse any of this content visit

https://www.bmj.com/company/products-services/rights-and-licensing/permissions/

BMJ Case Report Fellows may re-use this article for personal use and teaching without any further permission.

Become a Fellow of BMJ Case Reports today and you can:

- Submit as many cases as you like

- Enjoy fast sympathetic peer review and rapid publication of accepted articles

- Access all the published articles

Re-use any of the published material for personal use and teaching without further permission

Customer Service

If you have any further queries about your subscription, please contact our customer services team on +44 (0) 2071111105 or via email at support@bmj.com.

Visit casereports.bmj.com for more articles like this and to become a Fellow 